\title{
Smac Mimetic GDC-0152
}

National Cancer Institute

\section{Source}

National Cancer Institute. Smac Mimetic GDC-0152. NCI Thesaurus. Code C88274.

A second mitochondrial activator of caspases (Smac) mimetic inhibitor of IAPs (Inhibitor of Apoptosis Proteins) with potential antineoplastic activity. Smac mimetic GDC-0152 binds to the Smac binding groove on IAPs, including the direct caspase inhibitor $X$ chromosome-linked IAP (XIAP) and the cellular IAPs 1 and 2, which may inhibit their activities and promote the induction of apoptosis through apoptotic signaling pathways. IAPs are overexpressed by many cancer cell types and suppress apoptosis by binding to and inhibiting active caspases-3, -7 and -9 via their baculoviral IAP repeat (BIR) domains. Smac, the endogenous IAP antagonist, relies on its $\mathrm{N}$-terminal four amino-acid motif for binding to IAPs. 